\title{
Effect of Desulfurization Gypsum and Quicklime on Performance of Fly Ash Filling Paste
}

\author{
Yin Liu \\ State Key Laboratory of Mine Disaster \\ Prevention and Control \\ Shandong University of Science and \\ Technology \\ Qingdao, China \\ Liuyin-73@163.com \\ Yao $\mathrm{Lu}$ \\ State Key Laboratory of Mine Disaster \\ Prevention and Control \\ Shandong University of Science and \\ Technology \\ Qingdao, China \\ 723262355@qq.com
}

\author{
Boqiang Cui \\ State Key Laboratory of Mine Disaster \\ Prevention and Control \\ Shandong University of Science and \\ Technology \\ Qingdao, China, Corresponding author, \\ ybqcui1992@163.com \\ Ning Jiang \\ State Key Laboratory of Mine Disaster \\ Prevention and Control \\ Shandong University of Science and \\ Technology \\ Qingdao, China \\ jiangning198961@163.com
}

\author{
Changxiang Wang \\ State Key Laboratory of Mine Disaster \\ Prevention and Control \\ Shandong University of Science and \\ Technology \\ Qingdao, China \\ 1554624100@qq.com \\ Zhanxin Liu \\ Department of management \\ engineering \\ Shanxi Railway Institute \\ Weinan, China \\ 411814978@qq.com
}

\begin{abstract}
In order to reduce the filling cost and improve the coefficient of utilization of fly ash in coal mine filling paste, the influence of desulfurization gypsum and quicklime on the setting time and uniaxial compressive strength (UCS) of filling paste with large quantity of fly ash were studied using the control variable method, mechanical analysis, and other means. The hydration products and microstructures of the filling paste on corresponding age were analyzed by X-ray diffraction (XRD) and scanning electron microscopy (SEM), and results indicate the following: desulfurization gypsum can reduce the setting time of fly ash-filling paste and quicklime plays an important role in improving the late strength of fly ash-filling paste. When the cement and fly ash ratio in the gelling agent is 1:6, $8 \%$ of desulfurization gypsum can reach filling paste standards. When the quicklime is $4 \%$, the strength improvement has the best effect, but the setting time can't satisfy the filling paste standard, it can be meet the requirements of the filling paste when $4 \%$ quicklime and $4 \%$ desulfurization gypsum composite doped. XRD and SEM analysis illustrated that the difference in the types of hydration products and the amount of production at different times lead to different properties of the filling paste. Calcium hydroxide (CH) and a small amount of calcium silicate hydrate (CSH) are the main ingredients in the early stage of hydration products, filling paste activated by desulphurization gypsum generate ettringite (Aft) provides strength in the early age. The main hydration products of filling paste in the later stage are hydrated calcium aluminate (CAH), hydrated calcium aluminosilicate (CASH) and CSH.
\end{abstract}

Keywords-filling paste, fly ash, desulfurization gypsum, quicklime, gel activity

\section{INTRODUCTION}

In recent years, the technology of paste filling in coal mine has been developed rapidly in the field of mining [1-3]. As an important part of paste filling in coal mines, paste filling materials plays a vital role in mine safety production and cost control. The reuse of solid waste, such as coal gangue and construction waste, has made great progress [45]. Therefore, more and more coal mining enterprises control the filling cost by adding fly ash. As an industrial waste product, the vast majority of fly ash untreated and exposed accumulations causes environmental pollution, constitutes a waste of land resources, and poses significant risks to the human population. As a part of paste filling materials, fly ash has reduced its environmental pollution to some extent. Usually, companies only use it as a mixture to mix in filling paste [6-8], but ignore its potential gelling activity, thus restricting the development of fly ash paste filling materials.

At present, people are gradually paying attention to the activation of fly ash, but most of them are concentrated in the cement industry, there little research has been done on the coal mine paste filling materials. Activation of fly-ash activity is stimulated by many causes, including physical activation, chemical activation, thermal activation, compound activation, and others [9-11]. Among these, the high efficiency of chemical activation has been the concern of many researchers, and many basic results have been recorded [12-14]. Compared with cement, the content of $\mathrm{CaO}$ in fly ash is much lower than it, and $\mathrm{Ca}^{2+}$ is a necessary condition for the formation of gelling hydrates, therefore, many experts and scholars focus on the research of fly ash activator on the extensive sources of desulfurization gypsum and quicklime. Guo et al. [15] investigated the microstructures of gypsum and fly-ash adhesive using XRD, SEM, and pore structure analysis, which ultimately indicated that desulfurization gypsum can significantly improve the compressive strength and tensile bond strength of fly-ashcemented material. Mahdi et al. [16] adding desulfurization gypsum into fly ash-cement materials, use isothermal calorimetry, $\mathrm{pH}$ measurements, and other means, proved that the addition of desulfurized gypsum can effectively improve the uniaxial compressive strength of the concrete, and the concrete PH is finally close to neutral. Ke et al. [9] analyzed the principle of desulfurization gypsum's effect on the activity of a cement-fly-ash material theoretically, proved that the addition of $\mathrm{SO}_{4}{ }^{2-}$ and the generation of Aft can effectively improve the strength of Concrete. In their studies of quicklime as an activator, Antiohos [17] and Adam et al. [18] verified that the amount of lime can be used to control 
the cement-fly-ash slurry solidification time by strength tests and results in an increase of its strength. By measuring the compressive strength of the specimen, the early and late compressive strength of quicklime to cement-fly ash cementation has been studied, Singh et al [19] proved that the quicklime can significantly increase the later strength of the cement. S K Antiohos [20] et al use SEM to explore the hydration products of cement-fly ash cementation after adding quicklime, which proves that the quicklime can increases the reaction rate of high calcium fly ash and has a positive effect on the activity of low calcium fly ash. By means of TGA and XRD, Diego F. V. and Cyril L. [21] et al found that a certain amount of quicklime can enhance the activity of fly ash and replace part of cement.

There are also studies showing that if the compound activator is used rationally, its activation effect on fly ash is better than that of individual activation. Tao [22] and $\mathrm{Xu}$ et al. [23] used SEM and XRD to test the phase composition and microstructure of the fly-ash-based adhesive after the coactivation of desulfurized gypsum and quicklime, which proved the adhesive's gelation and the density enhancement. Li [24] and Sivapullaiah et al. [25] studied the apparent density, strength, and water absorption of quicklimegypsum-fly-ash adhesive and found that different amounts of desulfurized gypsum and quicklime have different effects on the activation of fly ash. Zhu et al. [26] selected I and II grade fly ash as full-tail-filling cementing materials and lime and gypsum as an activator to replace all the cement and explored the best ratio for tailings filling in the laboratory.

In summary, desulfurization gypsum and quicklime can improve the gel activity of fly ash to a certain extent. The filling paste of coal mine is different from concrete. The fly ash in its material can be used as aggregate or cementing material. However, at present, most coal mines usually use fly ash as aggregate, and their gel activation is often ignored. If the fly ash activity in the paste filling material can be fully activated, this will reduce the amount of cement in the filling material, so as to achieve the control of the filling cost. Therefore, the fly ash is used as a cementing material in this article, based on mining requirements for filling paste, we study the activation of desulfurization gypsum and quicklime to improve the compressive strength of fly ash filling material as well as setting times by using control variables, mechanical analysis, and other means. The hydration components of fly ash filling paste at different ages were analyzed by XRD, We analyze the microstructure distribution of cemented materials with a compound activator using SEM in a specific timeframe, to explore the fly-ash activity activation mechanism and provide technical references for enhancing the strength of cement-fly ashfilling material and improving the filling effect in coal mining. And combined with SEM to observe its corresponding micromorphology, so as to explore the activation mechanism of fly ash in filling paste and provide technical references for saving coal mine paste filling costs and improving utilization rate of fly ash.

\section{EXPERIMENTAL RAW MATERIALS AND EXPERIMENTAL METHODS}

\section{A. Experimental raw materials}

\section{(1) Coal gangue}

Coal mine abandoned coal gangue is used in this study. The coal gangue was broken and sieved with a $25 \mathrm{~mm}$ square sieve, less than $25 \mathrm{~mm}$ is used as the aggregate for filling paste.

\section{(2) Fly ash}

The fly ash was grade III type from a power plant in Shandong, its appearance was grayish brown, screening with $45 \mu \mathrm{m}$ square sieve, the remaining amount is $32 \%$, And the percentage of water requirement of standard consistency of $130 \%$. From Table I, it can be seen that the content of $\mathrm{SiO}_{2}$ and $\mathrm{Al}_{2} \mathrm{O}_{3}$ in fly ash is $46.84 \%$ and $28.25 \%$, respectively, which has potential gelation activity.

TABLE I. MAIN CHEMICAL COMPOSITION OF FLY ASH AND CEMENT (\%)

\begin{tabular}{|c|c|c|c|c|c|c|}
\hline Chemical composition & $\mathbf{C a O}$ & $\mathbf{S i O}_{\mathbf{2}}$ & $\mathbf{A l}_{\mathbf{2}} \mathbf{O}_{\mathbf{3}}$ & $\mathbf{F e}_{\mathbf{2}} \mathbf{O}_{\mathbf{3}}$ & $\mathbf{M g O}$ & $\mathbf{L o s s}$ \\
\hline Portland cement & 62.58 & 22.95 & 5.32 & 3.90 & 2.33 & 0.40 \\
\hline Fly ash & 8.13 & 46.84 & 28.60 & 4.01 & 1.79 & 12.73 \\
\hline
\end{tabular}

The morphology of fly ash was analyzed by scanning electron microscope. It was found that most of the particles were irregular clastic, mainly sponge like vitreous bodies, with little glass beads and uneven particle distribution. Fig. 1 showed the morphology of grade III fly ash under scanning electron microscope.

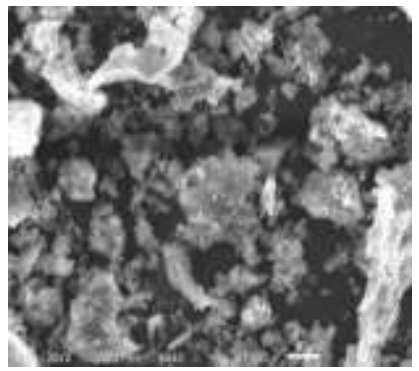

(a) Magnify 1000 times

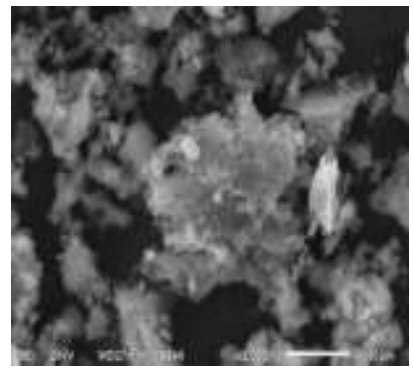

(b) Magnify 2000 times

Fig. 1 SEM image of grade III fly ash with different magnifications

\section{(3) Cement}

The cement was ordinary 32.5 Portland cement. The main chemical compositions of both are shown in Table 1 .

(4) Chemical activator

The chosen activator was desulfurization gypsum and quicklime in this study. The main component of the gypsum was $\mathrm{CaSO}_{4} \cdot 2 \mathrm{H}_{2} \mathrm{O}$ and the quicklime content of the $\mathrm{CaO}$ was $93 \%$.

\section{B. Experimental program}

The main components of the filling paste are cement, fly ash, coal gangue and water. In this study, in order to better compare the stimulating effect of the activator on the fly ash in the filled paste, the amount of fixed coal gangue is $60 \mathrm{wt} \%$ of the solids, the total amount of cement and fly ash is 
$40 \mathrm{wt} \%$ of the solids. The quality of the added activator are $4 \%, 8 \%$ and $12 \%$ of the total mass of fly ash and cement.
And the filling paste mass concentration is $74 \%$. The proportion of the mixture is shown in Table II .

TABLE II. COMPOSITION OF FLY ASH FILLING PASTE MATERIAL

\begin{tabular}{|c|c|c|c|c|c|}
\hline Filling paste & Cement & Fly ash & Coal gangue & Activator & Concentration \\
\hline Proportion & \multicolumn{2}{|c|}{$40 \%$} & $60 \%$ & $\begin{array}{c}0 \%, 4 \%, \\
8 \%, 12 \%\end{array}$ & $74 \%$ \\
\hline \multicolumn{7}{|r}{ Note: The activator is the percentage of the total mass of cement and fly ash }
\end{tabular}

The experimental procedure was as follows:

(1) Mixing material: first, the weighing material was poured into a NJ-160A cement paste mixer for mixing. After mixing the material evenly, the required quantity of water was added, and each sample of test material was stirred for $300 \mathrm{~s}$.

(2) The setting time determination: after mixing was completed, the setting time were determined immediately by vicat apparatus according to the test method outlined in China National Standard GBT1346-2001.

(3) Test block production: the remaining slurry was poured into a paste mold and molded to form a $100 \mathrm{~mm} \times 100$ $\mathrm{mm} \times 100 \mathrm{~mm}$ filling paste block. The filling paste block was numbered, put into standard curing box for conservation, for better downhole simulation, the curing conditions were set to a relative humidity of not less than $90 \%$ and a temperature of $25{ }^{\circ} \mathrm{C}$.

(4) UCS test: after a specified time, it was removed and subjected to strength testing by YAW-400 pressure testing machine. UCS test was repeated at least three times and the average was considered as the UCS of the tested sample.

(5) XRD diffraction analysis: a small portion of the sample was removed from the broken test block, and the hydrated alcohol was terminated in the anhydrous ethanol. After $24 \mathrm{~h}$, it was removed and dried, then grind, and screened with a $74 \mu \mathrm{m}$ sieves. The XRD diffraction experiment was made with the part less than $74 \mu \mathrm{m}$.

(6) SEM observation: after the strength test was completed, the sample is stopped hydration, then cut into small pieces and polished on the surface. The sample was dried in a drying oven at $70^{\circ} \mathrm{C}$ for 2 hours and then vacuumsprayed on a small sample. The sample was observed with a Hitachi S-4800 scanning electron microscope filling paste test piece of the hydration products microstructure.
Experimental flow chart shown in Fig. 2

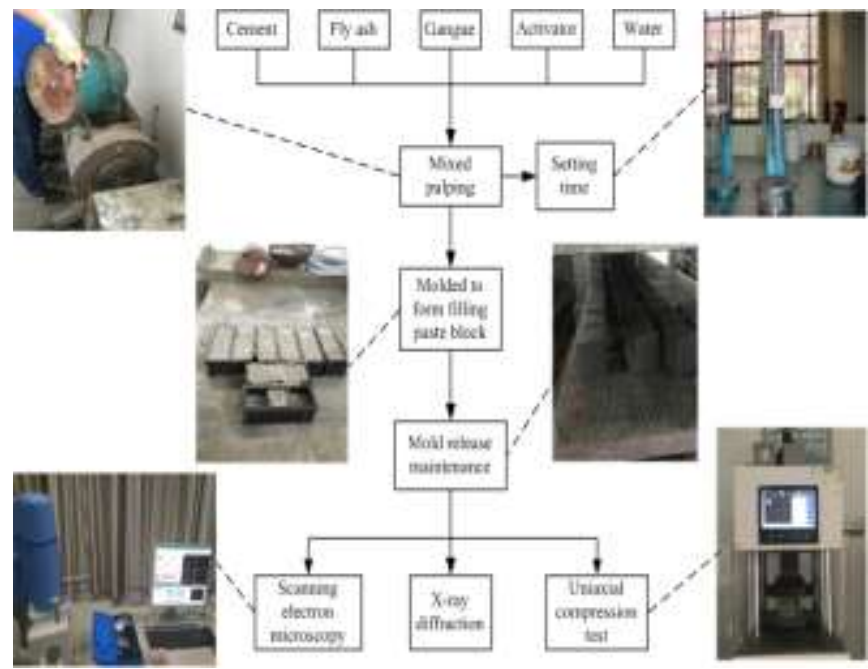

Fig. 2 Experimental flow chart

\section{EXPERIMENTAL RESULTS AND ANALYSIS}

\section{A. Optimal ratio of cement-fly ash composite cementation}

Although an excessive amount of cement can provide a very high strength of the filling paste, but it greatly increase the filling cost. The high efficiency required by coal production determines that the initial setting time of the filling paste be generally no more than $4 \mathrm{~h}$, the final setting time be $6-8 \mathrm{~h}$, the $1 \mathrm{~d}$ strength of the filling paste be not less than $0.1 \mathrm{MPa}$, and the $28 \mathrm{~d}$ compressive strength be not less than 3.0 MPa. Therefore, we first explored the optimal ratios of cement and fly ash in order to reduce the filling cost to provide reference ratios. The amount of the fixed coal gangue is $60 \mathrm{wt} \%$ of the total mass in this study, optimal ratio of cement-fly ash composite cementation experimental design and results are shown in Table III.

TABLE III. EXPERIMENTAL DESIGN AND RESULTS FOR CEMENT-FLY ASH SYSTEM

\begin{tabular}{|c|c|c|c|c|c|c|c|c|}
\hline \multirow{2}{*}{ Number } & \multirow{2}{*}{$\begin{array}{c}\text { Solid ratio } \\
\text { Cement:fly ash }\end{array}$} & \multirow{2}{*}{$\begin{array}{l}\text { Content of fly } \\
\text { ash }\end{array}$} & \multirow{2}{*}{$\begin{array}{l}\text { Content of } \\
\text { coal gangue }\end{array}$} & \multicolumn{2}{|c|}{ Setting time $/ \mathrm{h}$} & \multicolumn{3}{|c|}{ UCS/MPa } \\
\hline & & & & Initial & Final & 1d & 7d & 28d \\
\hline 01 & $0: 1$ & $40.0 \%$ & \multirow{7}{*}{$60 \%$} & -- & -- & -- & -- & -- \\
\hline 02 & 1:0 & $0 \%$ & & 2.0 & 3.30 & 3.8 & 20.1 & 25.8 \\
\hline 03 & $1: 2$ & $26.7 \%$ & & 2.38 & 6.50 & 0.62 & 3.15 & 5.65 \\
\hline 04 & $1: 3$ & $30.0 \%$ & & 2.73 & 6.75 & 0.54 & 2.95 & 4.75 \\
\hline 05 & $1: 4$ & $32.0 \%$ & & 3.12 & 7.15 & 0.47 & 2.73 & 4.12 \\
\hline 06 & $1: 5$ & $33.3 \%$ & & 3.50 & 8.25 & 0.38 & 2.67 & 3.59 \\
\hline 07 & $1: 6$ & $34.3 \%$ & & 4.15 & 9.55 & 0.27 & 2.12 & 2.71 \\
\hline
\end{tabular}

As can be seen from Fig. 3, cement has a very strong gelling property, which can coagulation in a short time and reach a certain strength. The initial and final setting times are prolonged with increasing fly ash content on the fly ash filling paste. Filling paste can't be coagulation while cement is completely replaced by fly ash. When the ratio of cement 
to fly ash content reaches $1: 5$, that is, when the amount of fly ash in the filling paste reaches $33.3 \%$ of the total mass, the final setting time of the system is more than $8 \mathrm{~h}$, which is slightly larger than the requirement for final setting time of coal mining. It can be seen from USC, the fly ash itself does not bond to produce strength. For the cement with different fly ash contents, the compressive strength at the specified time decreases with decreasing cement content in the gel system. When the cement and fly ash content are in a proportion between 1:2 and 1:5, the early-stage and latestage strengths of the filling paste are basically in accordance with the requirement of coal paste filling. When the content of fly ash is $34.3 \%$ (cement : fly ash=1:6), the UCS of the filling paste test blocks at 28 days is $2.71 \mathrm{MPa}$, which has an adverse effect on the backfill mining.

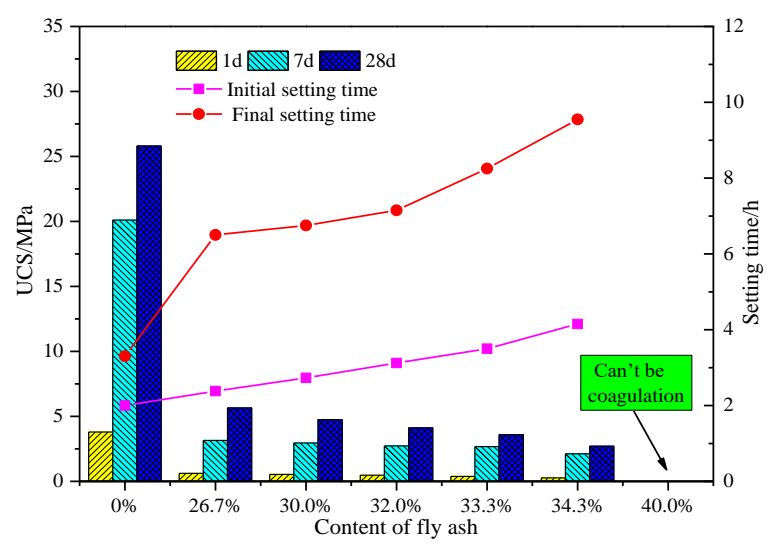

Fig. 3 Effect of fly ash content on setting time and UCS of filling paste It can be seen from this experiment, when the content of coal gangue is $60 \mathrm{wt} \%$, the content of fly ash less than $34.3 \mathrm{wt} \%$, and the mass concentration is $74 \%$, filling paste can basically meet the needs of mine safety production. When no activator is added, considering that the cement and fly ash ratio is $1: 5$, the final setting time of filling paste is slightly larger than that of $8 \mathrm{~h}$, the ratio of $1: 4$ for cement and fly ash can be selected as the best ratio. In order to reduce the filling cost and avoid the waste of resources caused by excessive strength, it can also meet the safety production of the mine, and combined with coagulation time, an optimum ratio of the content of cement and fly ash of 1:6 is used to research the optimum amount of activator.

\section{B. Effect of chemical activator on properties of fly ash filling paste}

The activity of fly ash in the filling paste is activated by different activators, and the content of each component of the filling paste remains unchanged, and the amount of its activator and the experimental results are shown in Table IV.

From table IV, the following conclusions can be drawn: The effect of different activators on the fly ash filling paste is different. The same activator but different dosage have different effects on the properties of filling paste.

TABLE IV. EFFECT OF DESULFURIZATION GYPSUM ON FLY ASH FILLING PASTE

\begin{tabular}{|c|c|c|c|c|c|c|c|c|}
\hline \multirow{2}{*}{ Number } & \multirow{2}{*}{$\begin{array}{c}\text { Solid ratio } \\
\text { Cement: fly ash }\end{array}$} & \multirow{2}{*}{$\begin{array}{c}\text { Content of } \\
\text { desulfurization } \\
\text { gypsum } \\
\end{array}$} & \multirow{2}{*}{$\begin{array}{l}\text { Content of } \\
\text { quicklime }\end{array}$} & \multicolumn{2}{|c|}{ Setting/h } & \multicolumn{3}{|c|}{ UCS/MPa } \\
\hline & & & & Initial & Final & 1d & $7 d$ & 28d \\
\hline 07 & \multirow{9}{*}{$1: 6$} & $0 \%$ & $0 \%$ & 4.15 & 9.55 & 0.27 & 2.12 & 2.71 \\
\hline A2 & & $8 \%$ & $0 \%$ & 3.55 & 7.85 & 0.43 & 2.42 & 3.15 \\
\hline A3 & & $12 \%$ & $0 \%$ & 4.25 & 10.45 & 0.40 & 2.28 & 2.89 \\
\hline B1 & & $0 \%$ & $4 \%$ & 4.25 & 10 & 0.26 & 2.55 & 3.35 \\
\hline $\mathbf{B 3}$ & & $0 \%$ & $12 \%$ & 4.75 & 10.55 & 0.22 & 2.54 & 3.11 \\
\hline C1 & & $4 \%$ & $4 \%$ & 3.95 & 8.35 & 0.31 & 2.25 & 3.22 \\
\hline $\mathrm{C2}$ & & $4 \%$ & $8 \%$ & 4.35 & 9.55 & 0.40 & 2.35 & 3.02 \\
\hline $\mathrm{C3}$ & & $8 \%$ & $4 \%$ & 3.75 & 8.15 & 0.43 & 2.35 & 3.08 \\
\hline C4 & & $8 \%$ & $8 \%$ & 4.25 & 9.75 & 0.52 & 2.58 & 3.12 \\
\hline
\end{tabular}

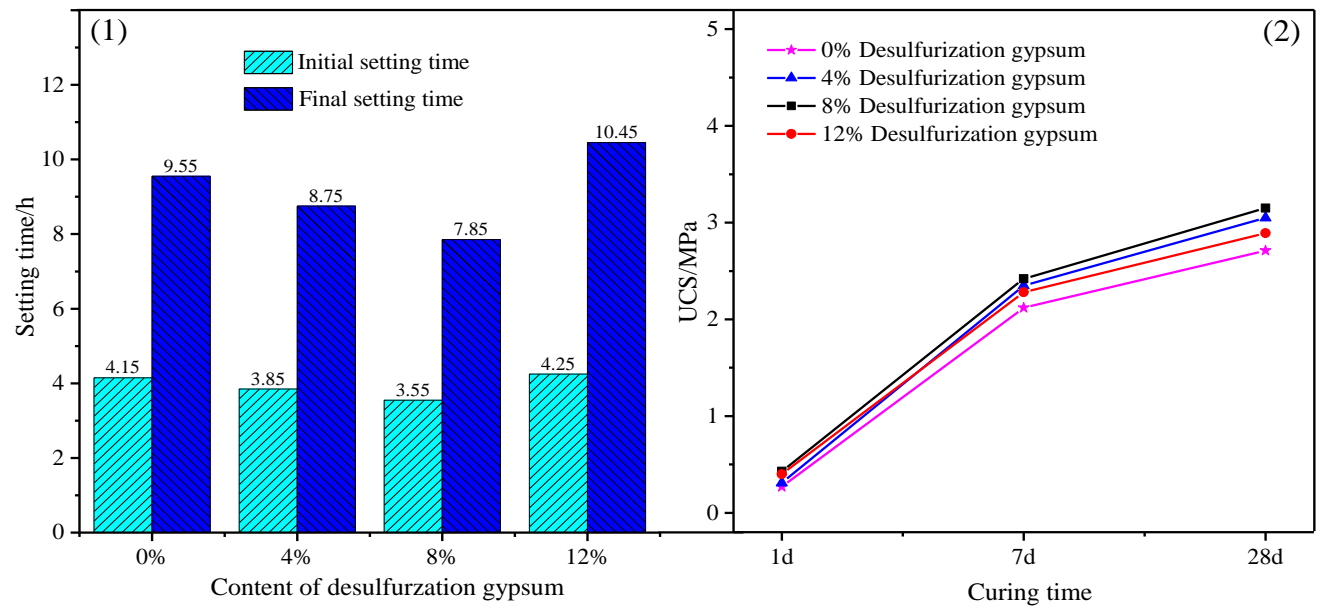

Fig. 4 Effect of desulfurization gypsum content on fly ash filling paste 
It can be seen from Fig. 4 that desulphurization gypsum has certain effect on the properties of fly ash filling paste, especially in improving the setting time of filling paste. From Fig. 4(1), it can be seen that when the content of desulfurization gypsum is less than $8 \%$, the setting time of the filling paste is shortened with the increase of the amount of fly ash. When the content of desulfurization gypsum is $8 \%$, the initial setting time of filling paste is $3.55 \mathrm{~h}$, and the final setting time is $7.85 \mathrm{~h}$, all these meet the requirement of coal production for filling paste setting time. However, when the content of desulfurization gypsum is increased to $12 \%$, the initial time and final time of filling paste increased greatly, compared with filling paste which not added desulfurization gypsum, its final setting time increased by $9.4 \%$, which is go against to safe production of coal mines. It can be seen from Fig. 4(2), after incorporation of desulfurization gypsum, the UCS of the filling paste at various ages is relatively increased. When the mixing amount of desulfurization gypsum is $8 \%$, the USC of filling paste test blocks in each age reached the optimum value, and the strength can reach $3.15 \mathrm{MPa}$ at 28 days. When the content of desulphurization gypsum is $12 \%$, its strength is relatively low at all stages. It shows that the desulfurization gypsum has been overdose at this time, this is unfavorable to the fly ash filling paste.

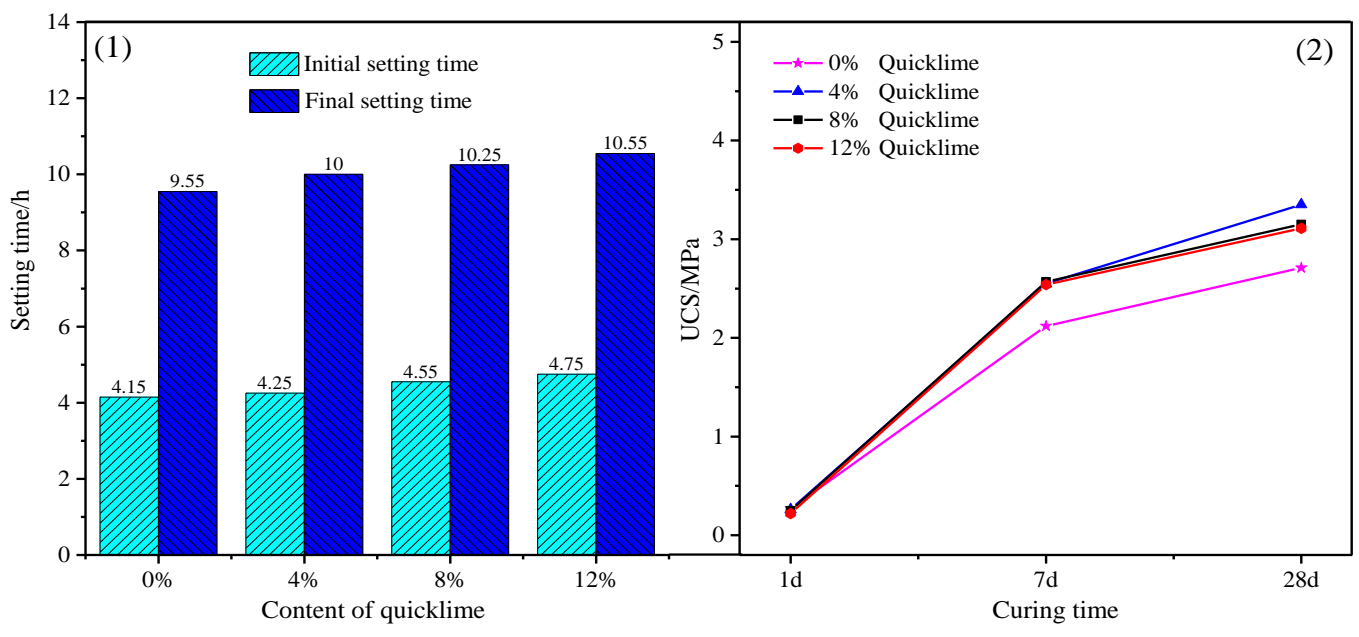

Fig. 5 Effect of quicklime content on fly ash filling paste

Fig. 5 shows the effect of quicklime content on the setting time and UCS of fly ash filling paste. It can be seen from Fig. $5(1)$, with the increase of quicklime consent, the initial setting time and final setting time of filling paste have been greatly prolonged, and their final setting time is no less than $10 \mathrm{~h}$, which means that quicklime will have an adverse effect on the setting time of filling paste, thus affecting the whole filling. In terms of strength, the effect of quicklime on the early-stage compressive strength of the filling body is not significantly affected, but its late-stage compressive strength is significantly improved. From Fig. 5(2), it can be seen that after incorporation of quicklime in the filling paste, the UCS of the filling paste test blocks are above $3 \mathrm{Mpa}$ at the later stage, especially when the content of quicklime is $4 \%$, the UCS of $28 \mathrm{~d}$ is increased by $15.1 \%$. However, when the content of quicklime is more than $4 \%$, the UCS of the fly ash filling paste decreases gradually, indicating that excessive quicklime is not conducive to the development of the strength of the fly ash filling paste.

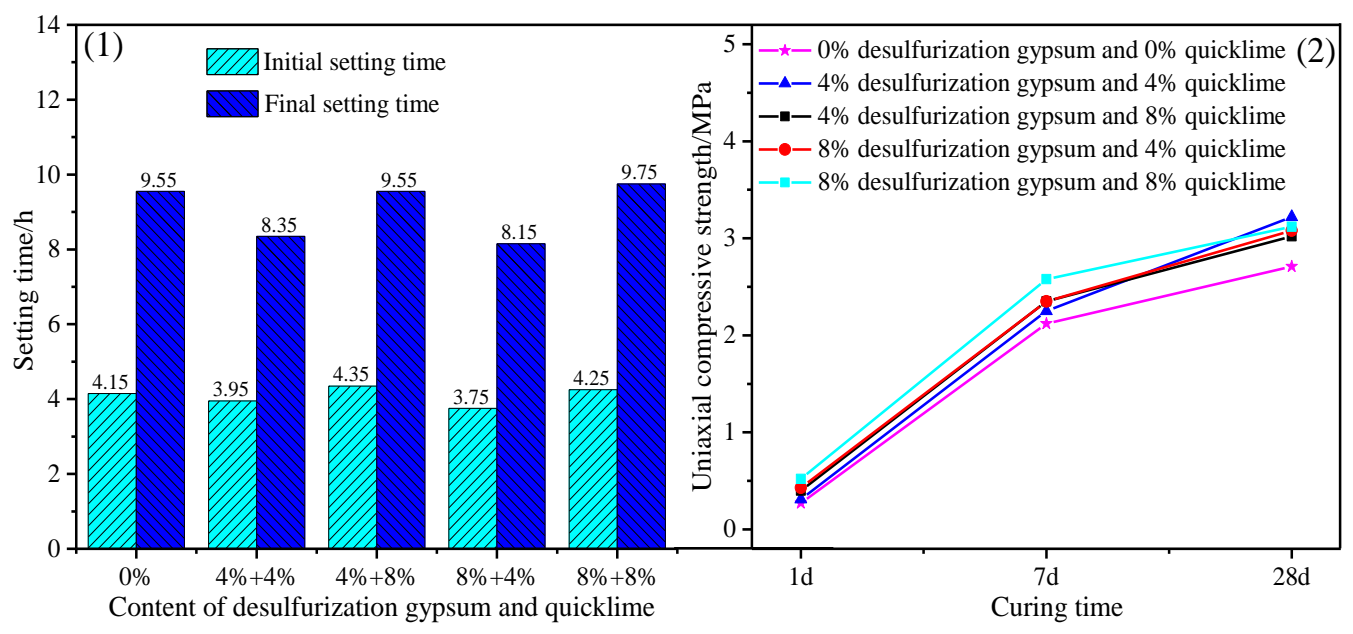

Fig. 6 Effect of compound activator content on fly ash filling paste

After the addition of desulfurization gypsum and quicklime, effect of compound activator content on USC and setting time for fly ash filling paste show in Fig. 6. From Fig.
6 (1), it can be seen that when the amount of desulfurization gypsum added to the fly ash filling paste is greater than that of quicklime, the setting time of the filling paste can be 
shortened. With increasing desulfurization gypsum content, the initial and final setting times of the fly ash filling paste are significantly less than that of the cemented quicklime. When the content of desulfurization gypsum is $8 \%$ and the content of quicklime is $4 \%$, the final setting time of filling paste is reduced by $14.7 \%$. The strength of the adhesive is not much higher than that of the single chemical activator, but its late-stage strength increases greatly, reaching 11.4$18.8 \%$, compared with the addition of desulfurization gypsum, the compound chemical activator increases the later-stage strength. However, the amount of activator is not the more the better. When the amount of desulfurization gypsum and quicklime are $8 \%$, the initial setting time and final setting time are slightly longer, which is not conducive to the safety of mine production.

The experiment shows that desulfurization gypsum and quicklime have certain influence on the properties of fly ash filling paste in a certain range of dosage. Desulfurization gypsum can not only adjust the setting time of fly ash filling paste, but also has a certain increase in strength. When the content of desulfurization gypsum is $8 \%$, it can meet the performance requirement of filling paste for mines. Quicklime can improve the uniaxial compressive strength of fly ash filling paste at later stage, when its content is $4 \%$, the strength increases to get the best effect, but the setting time does not meet the standard of filling paste. Therefore, it is recommended that $4 \%$ of quicklime and $4 \%$ of desulfurized gypsum be compounded to stimulate, so as to meet the performance of the fly ash filling paste.

\section{Microstructure analysis of fly ash filling paste}

In order to explore the mechanism of the activation of fly ash filling paste by desulfurization gypsum and quicklime, we analyzed corresponding hydration products of fly ash filling paste with no activator, $8 \%$ desulfurization gypsum and $4 \%$ quicklime by X-ray diffraction (XRD). And use scanning electron microscopy (SEM) to observe the solid state of the specified age. The results are shown in the following figures.

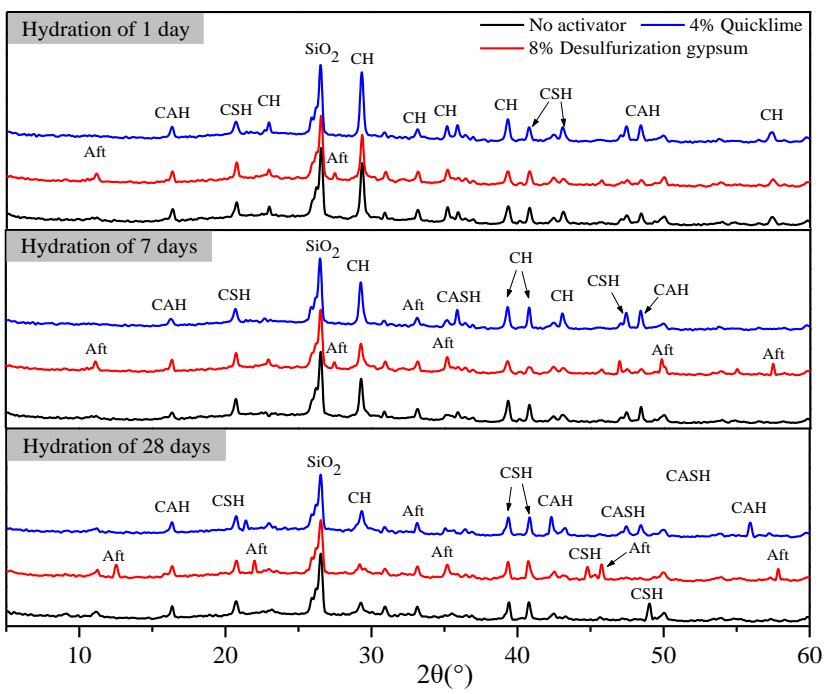

Fig. 7 XRD of hydration products in various ages of fly ash filling paste under different activator

As shown in Fig. 7, the hydration products of fly ash paste filling with different activators are obviously different. The hydration products of fly ash filling paste are mainly calcium hydroxide $(\mathrm{CH})$, hydrated calcium silicate $(\mathrm{CSH})$ and calcium aluminate hydrate $(\mathrm{CAH})$ at 1 day. This moment, the $\mathrm{CH}$ peak in the fly ash paste filling which added with quicklime is obviously more than those in the other two groups. While the XRD of the fly ash filling paste added with desulphurization gypsum appears ettringite (Aft), and its $\mathrm{CH}$ peaks are relatively weak, this shows that at this time, a large amount of $\mathrm{CH}$ has been Participation reaction involved generate new substances in the fly ash filling paste which addition of desulfurization gypsum, this may be the reason for its early strength enhancement. It can be seen from Fig. 8 (a), SEM shows that many mineral phases and crystalline phases are separated from each other in the fly ash filling paste with no activator, and there is a certain gap. A very small amount of acicular Aft appeared in the filling paste test block that added with desulphurization gypsum, fill in gaps of the filling paste test blocks. In the fly ash filling paste mixed with quicklime, a large amount of flaky $\mathrm{CH}$ is generated and interlaced with CSH.
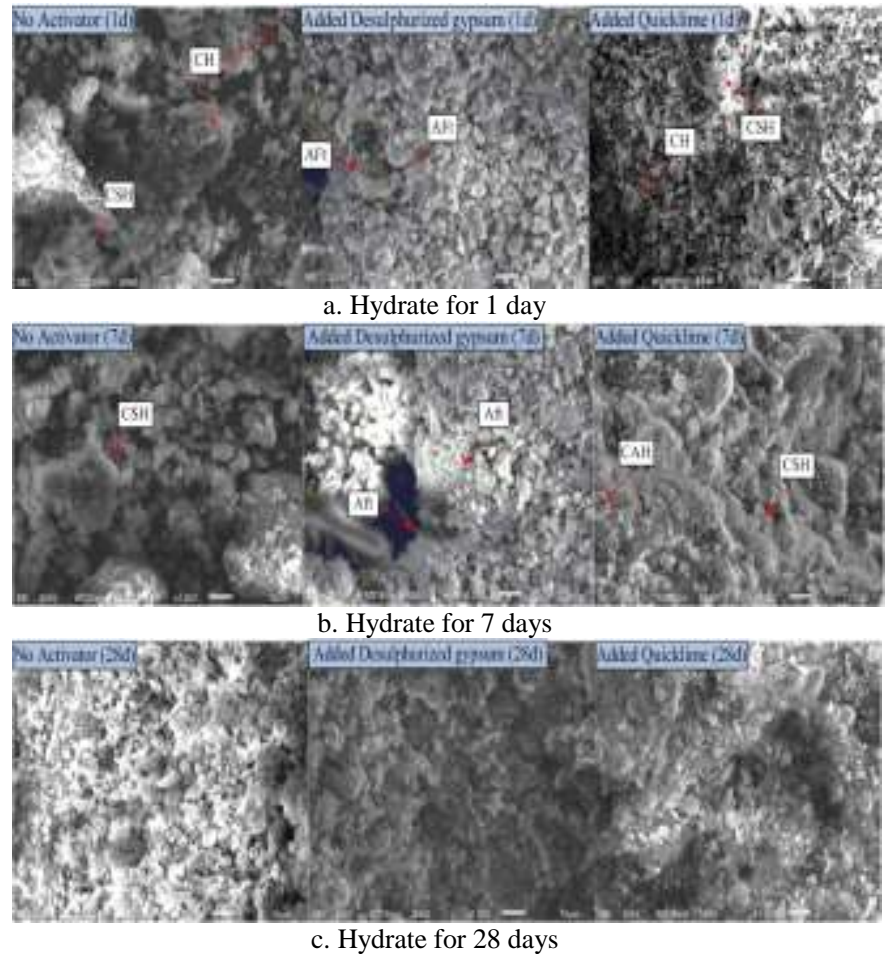

Fig. 8 SEM images of different hydration times of fly ash filling paste with different activator (a. Hydrate for 1 day, b. Hydrate for 7 day, c. Hydrate for 28 day)

When the fly ash filling paste hydrate for 7days, the $\mathrm{CH}$ peaks in the hydration products of three groups of filling paste test blocks obviously decreased. Among them, the CSH and $\mathrm{CAH}$ peaks in the hydration products obviously increased in the filling paste test blocks without activator and the filling paste test blocks with quicklime. In addition, a large amount of hydrated calcium alum inosilicate (CASH) peaks appeared in the fly ash filling paste mixed with quicklime. At this time, the Aft peaks in the filling paste added with desulfurization gypsum increased, while the $\mathrm{CAH}$ peaks decreased. As can be seen from Fig. 8 (b), at this stage, the three groups of filling pastes test blocks began to become dense. SEM shows that a large amount of CSH was generated by the filling paste without activator, and a large 
number of acicular Aft was produced in the filling paste that added with desulfurization gypsum, and the amount of CSH produced in the filling paste which added with quicklime was more than that of a group without activator.

When the hydration reaction proceeds to 28days, it can be seen from XRD, the $\mathrm{CH}$ peaks almost disappeared, and no new substances were produced in the hydration products of the filling paste test blocks of each group, and the increase of the existing substances also tended to be gentle. From Fig. 8 (c), it can be seen the internal structure of the fly ash filling paste Hydrate for 28 days is more dense, and there is very little void. At this time, the fly ash filling paste mixed with quicklime has the best compactness. For filling paste that added with desulfurization gypsum, a significant change is that the production of acicular Aft is gradually reduced; however, various hydrates, such as $\mathrm{CSH}$ and $\mathrm{CAH}$, have become interwoven and coupled with each other to promote the steady growth of late-stage strength of the fly ash filling paste.

It can be seen from XRD and SEM, the hydration products of fly ash filling paste in different periods have a significant effect on the setting time and uniaxial compressive strength of filling paste. An appropriate amount of desulfurization gypsum can excite the active material in the fly ash, and generate ettringite filled with the gel in the filling paste, filling in the gap, and enhancing the early strength of the filling paste. The appropriate amount of quicklime can react with the active material in the fly ash to form the gel products necessary to filling paste to provide strength.

\section{Action mechanism of activator in fly ash filling paste}

Through the above study, it is found that different activators have different excitation effects on fly ash filling pastes. The same activator and different mixing amount have different effects on the properties of fly ash filling paste. The stimulating effect of the activator on the fly ash filling paste mainly depends on the excitation of the active material in the fly ash.

Activated $\mathrm{SiO}_{2}$ and $\mathrm{Al}_{2} \mathrm{O}_{3}$ in fly ash can react with $\mathrm{CH}$ released from the hydration of cement and other clinker minerals. In an alkaline environment, the $\mathrm{Si}-\mathrm{O}$ and $\mathrm{Al}-\mathrm{O}$ bonds in the components are broken and the glass phase gradually dissolves. The silicon oxide in the vitreous starts to hydrate, producing a large amount of $\mathrm{CSH}, \mathrm{CAH}$ and $\mathrm{CASH}$, which provides strength for the gel system. This involves the following chemical formulas [27]:

$$
\begin{aligned}
& \mathrm{SiO}_{2}+\mathrm{Ca}(\mathrm{OH})_{2}+\mathrm{H}_{2} \mathrm{O} \rightarrow \mathrm{CaO} \cdot \mathrm{SiO}_{2} \cdot \mathrm{xH}_{2} \mathrm{O}, \\
& \mathrm{Al}_{2} \mathrm{O}_{3}+\mathrm{Ca}(\mathrm{OH})_{2}+\mathrm{H}_{2} \mathrm{O} \rightarrow \mathrm{CaO} \cdot \mathrm{Al}_{2} \mathrm{O}_{3} \cdot \mathrm{xH}_{2} \mathrm{O}, \\
& \mathrm{Al}_{2} \mathrm{O}_{3}+\mathrm{Ca}(\mathrm{OH})_{2}+2 \mathrm{SiO}_{2}+3 \mathrm{H}_{2} \mathrm{O} \rightarrow \mathrm{CaO} \cdot \mathrm{Al}_{2} \mathrm{O}_{3} \cdot 2 \mathrm{SiO}_{3} \cdot 4 \mathrm{H}_{2} \mathrm{O} .
\end{aligned}
$$

The addition of desulfurization gypsum provides $\mathrm{SO}_{4}{ }^{2-}$ and $\mathrm{Ca}^{2+}$ for the fly ash filling paste. Active $\mathrm{Al}_{2} \mathrm{O}_{3}$ released from the dissolution of fly ash and calcium aluminate hydrate produced by hydration of cement clinker react to produce Aft under the action of $\mathrm{SO}_{4}{ }^{2-}$, while providing strength and consuming a large amount of $\mathrm{AlO}^{2-}$ and $\mathrm{Ca}^{2+}$ in the adhesive. The decrease of $\mathrm{CH}$ content promotes the hydration of $\mathrm{CaO}$ and $\mathrm{SiO}_{2}$ in cement clinker, so that the concentration of adhesive $\mathrm{CH}$ is increased. This, in turn, facilitates the dissolution of fly ash and the formation of Aft; these two materials effectively promote each other so that fly-ash activity is more likely to be fully activated and increase the strength of the slurry. Therefore, Aft is a key factor in increasing the early strength of filling pastes when the activator is desulfurization gypsum. The main reaction is as follows [28]:

$$
\mathrm{AlO}_{2}-+\mathrm{Ca}^{2+}+\mathrm{OH}-+\mathrm{SO}_{4}{ }^{2-} \rightarrow 3 \mathrm{CaO} \cdot \mathrm{Al}_{2} \mathrm{O}_{3} \cdot 3 \mathrm{CaSO}_{4} \cdot 32 \mathrm{H}_{2} \mathrm{O} .
$$

Excessive amounts of desulfurization gypsum will result in the presence of hemihydrate gypsum in the fly ash filling paste. In addition, with the continuous dissolution of fly ash vitreous active $\mathrm{Al}_{2} \mathrm{O}_{3}$, the filling paste generates more and more Aft, and since both substances are expandable, they are produced in such high amounts that they cause a decrease in the strength of the filling paste. When the mixing amount is $12 \%$, Because of its excessive stimulation, a large amount of Aft is generated, which leads to an increase in the internal stress of the filling paste, and is not conducive to the strength of the filling paste.

The type of hydration products of the fly ash filling paste mixed with quicklime is the same as that of the filling paste without additives. It can be seen from Fig. 8, the stimulation effect of quicklime on paste filled with fly ash is manifested in the amount of hydration products. Quicklime mixed with filling paste after the rapid reaction with water to produce $\mathrm{CH}$ provides $\mathrm{Ca}^{2+}$ ions. In the early stage of the reaction, formation of a large number of $\mathrm{CH}$ is not conducive to the formation strength of filling paste, therefore, with the increase of quicklime content, the setting time of filling paste gradually increases. As the reaction progresses, the continuous generation of $\mathrm{CH}$ provides an alkaline environment for the activation of fly ash, and the glass phase in the fly ash gradually dissolves, and the $\mathrm{Si}-\mathrm{O}$ and $\mathrm{Al}-\mathrm{O}$ bonds in the active $\mathrm{SiO}_{2}$ and $\mathrm{Al}_{2} \mathrm{O}_{3}$ are broken, reacts with $\mathrm{CH}$ to produce lots of $\mathrm{CSH}$ and $\mathrm{CASH}$, which provides strength, further promoting the fly ash activation process, increase the late strength of filling paste.

\section{CONCLUSIONS}

In this study, the effects of different contents of desulfurization gypsum and quicklime, single doped and double doped, on the properties of filling paste were studied. The hydration products and microstructures of the filling paste on corresponding age were analyzed by X-ray diffraction (XRD) and scanning electron microscopy (SEM), this is of great significance for saving the cost of coal paste filling and improving the utilization rate of fly ash. The following conclusions were drawn:

(1) Both desulfurization gypsum and quicklime can stimulate the activity of fly ash, the desulfurization gypsum can reduce the setting time of the fly ash filling paste, and the quicklime plays an important role in the improvement of the later strength of the filling paste.

(2) In the filling paste with ash material ratio of 2:3, the ratio of cement to fly ash is $1: 6$, when the desulfurization gypsum content is $8 \%$, it can meet the performance 
requirements of mines for filling pastes; when the quicklime content is $4 \%$, the strength increases to get the best effect, but the setting time does not meet the standard of filling paste. Therefore, it is recommended that $4 \%$ of quicklime and $4 \%$ of desulfurized gypsum be compounded to stimulate, so as to meet the performance of the fly ash filling paste.

(3) It can be seen from XRD and SEM, the early hydration products of the fly ash filling paste were mainly calcium hydroxide $(\mathrm{CH})$, with a small amount of calcium silicate hydrate $(\mathrm{CSH})$, in the filling paste mixed with desulphurization gypsum, Aft was formed at the early stage to provide strength for filling paste. The hydration products in the late of filling paste are mainly calcium aluminate hydrate $(\mathrm{CAH}), \mathrm{CSH}$ and hydrated calcium alum inosilicate (CASH).

(4) The effect of activator on the performance of fly ash filling paste is mainly manifested by the amount of hydration product. A suitable amount of activator can effectively control the output of hydration products and improve the performance of filling paste. And excessive activator may result in failure of excitation.

\section{ACKNOWLEDGEMENTS}

This research was supported by China Coal Industry Association Science and Technology Research Guidance Project (MTKJ2016-277); Grants from Natural Science Foundation of Shandong Province (ZR2017MEE055), Key Project of Green and High Efficiency Mining and Comprehensive Utilization of Mineral Resources in Henan Province (s201609)

\section{REFERENCES}

[1] X. G. Zhang, J. Li, J. X. Liu, F. Li, and Z. Z. Pang, "Investigation of hydraulic-mechanical properties of paste backfill containing coal Gangue-Fly Ash and its application in an underground coal mine," Energies, vol. 10, pp. 1309, 2017.

[2] F. Moisés, R. Olga, V. V. Raquel, G. Rosario et al., "The influence of activated coal mining wastes on the mineralogy of blended cement pastes," Journal of the American Ceramic Society, vol. 99, pp. 300307, 2016.

[3] J. W. Zhang, H. L. Wang, and S. J. Chen, "Bearing capacity of backfill body and roof stability during strip coal pillar extracted with paste backfill," Geotechnical and Geological Engineering, vol. 36, pp. 235-245, 2018.

[4] D. W. Yin, S. J. Chen, X. Q. Liu, and H. F. Ma, "Effect of joint angle in coal on failure mechanical behavior of roof rock-coal combined body," Quarterly Journal of Engineering Geology \& Hydrogeology, vol. 51, pp. 202-209, 2018.

[5] D. Wu, Y. B. Hou, T. F. Deng, Y. Z. Chen, and X. L. Zhao, "Thermal, hydraulic and mechanical performances of cemented coal gangue-fly ash backfill," International Journal of Mineral Processing, vol. 168, pp. 12-18, 2017.

[6] A. Ren, G. R. Feng, Y. X. Guo et al., "Influence on performance of coal mine filling paste with fly ash," Journal of China Coal Society, vol. 39, pp. 2374-2380, 2014.

[7] A. G. Doven, and A. Pekrioglu, "Material properties of high volume fly ash cement paste structural fill," Journal of Materials in Civil Engineering, vol. 17, pp. 686-693, 2005.

[8] L. L. Wu, K. T. Kang, B. Yin, and M. Z. Du, "Microcalorimetric test and analysis of hydration heat of fly ash paste-filling material," Journal of China Coal Society, vol. 40, pp. 2801-2806, 2015.
[9] G. J. Ke, X. F.Yang, H. Peng, F. Jia, and H. T. Yue, "Progress of research on chemical activating mechanisms of fly ash," Journal of China Coal Society, vol. 30, pp. 366-370, 2005.

[10] X. Q. Lin, D. M. Wang, C. Y. Xu, J. H. Zhao, and F. H. Han, "Effects of sulfates and chloride promoters on fly ash activity," Fly Ash, vol. 01, pp. 4-7, 2012.

[11] G. R. Feng, Y. F. Ren, X. Y. Zhang et al., "Experimental study on fly ash activity excitation in Tashan mine," Journal of Coal Science, vol. 36, pp. 732-737, 2011

[12] P. Barbara, I. Wilińska, and G. Blonkowski, "Investigations of cement early hydration in the presence of chemically activated fly ash," Journal of Thermal Analysis and Calorimetry, vol. 93, pp. 769776, 2008.

[13] S. Kiatsuda, J. Cha, K. Puangrat, and C. Prinya, "NaOH-activated ground fly ash geopolymer cured at ambient temperature," Fuel, vol. 90, pp. 2118-2124,2011.

[14] W. M. Cheng, X. M. Hu, J. Xie, and Y. Y. Zhao, "An intelligent gel designed to control the spontaneous combustion of coal: Fire prevention and extinguishing properties," Fuel, vol. 210, pp. 826-835, 2017.

[15] X. L. Guo, H. S. Shi, and A. D. Warren, "Utilization of thermally treated flue gas desulfurization (FGD) gypsum and class-C Fly Ash (CFA) to prepare CFA-based geopolymer," Journal of Wuhan University of Technology-Mater. Sci. Edm, vol. 28, pp. 132-138, 2013.

[16] M. Mahyar, S. T. Erdoğan, "Phosphate-activated high-calcium fly ash acid-base cements," Cement \& Concrete Composites, vol. 63, pp. 96103, 2015.

[17] S. Antiohos, S. Tsimas, "Activation of fly ash cementitious systems in the presence of quicklime Part I. Compressive strength and pozzolanic reaction rate," Cement and Concrete Research, vol. 34, pp.769-779, 2004.

[18] A. A. Adam, N. H. Amiri, I. W. Suarnita, and N. Rupang, "The Effect of Lime Addition on the Setting Time and Strength of Ambient Cured Fly Ash Based Geopolymer Binder," Matec Web of Conferences, vol. 47, pp. 1015, 2016.

[19] G. Singh, and K. Subramaniam, "Concrete using Siliceous Fly ash at very High Levels of Cement Replacement: Influence of Lime Content and Temperature," Rn Raikar Memorial Intl Conference \& Banthia-ba, 2016.

[20] S. K. Antiohos, A. Papageorgiou, V. G. Papadakis, and S. Tsimas, "Influence of quicklime addition on the mechanical properties and hydration degree of blended cements containing different fly ashes," Construction and Building Materials, vol. 22, pp. 1191-1200, 2008

[21] F. V. Diego, J. L. Cyril, L. P. John, R. Fernando, and C. G. Ana, "Evaluation of activated high volume fly ash systems using $\mathrm{Na}_{2} \mathrm{SO}_{4}$, lime and quicklime in mortars with high loss on ignition fly ashes," Construction and Building Materials, vol. 128, pp. 248-255, 2016.

[22] W. H. Tao, Z. M. Liu, M. X. Zhang, and X. H. Fu, "The desulfurization gypsum-lime- gelation and hydration mechanism of fly ash system," Journal of Jinan University (natural science edition), vol. 03, pp. 233-237, 2010.

[23] Z. F. Xu, M. X. Zhang, and H. X. Xu, "Limestone-gypsum-the hydration mechanism of fly ash-cement study," Journal of environmental engineering, vol. 10, pp. 1879-1884, 2009.

[24] J. Li, F. Q. Zhang, G. Li, Y. W. Ma et al., "Quick lime to fly ash and gypsum composite material modification research," Journal of nonmetallic mineral, vol. 5, pp. 52-54, 2016.

[25] P. V. Sivapullaiah, and A. B. M. Arif, "CBR and strength behavior of class F fly ashes stabilized with lime and gypsum," International Journal of Geotechnical Engineering, vol. 5, pp. 121-130,2011.

[26] L. P. Zhu, W. Ni, D. Huang, M. Hui, and S. J. Gao, "All the backfilling of fly ash," Journal of cemented filling journal of Beijing University of science and technology, vol. 10, pp. 1190-1196, 2011.

[27] T. S. He, and G. Q. Wei, "Effects of Activator Type on Strength of Cement Mortar with Different Fly Ash," Content, vol. 05, pp. 6264,2009

[28] G. S. Li. "Sulfate resistance of fly ash concrete (English)," Journal of the Chinese Ceramic Society, vol. 40, pp. 39-48, 2012. 